\title{
PROTOTIPE SISTEM INFORMASI KETINGGIAN AIR MELALUI MEDIA SOSIAL TWITTER SEBAGAI SISTEM PERINGATAN DINI BAHAYA BANJIR
}

\section{PROTOTYPE OF WATER LEVEL INFORMATION SYSTEM THROUGH SOCIAL MEDIA TWITTER AS EARLY WARNING SYSTEM OF A FLOOD HAZARD}

\author{
Devin Ardi Dwiraharja ${ }^{1}$, Hidayat Nur Isnianto \\ ${ }^{1}$ Program Diploma III Teknik Elektro, Sekolah Vokasi, Universitas Gadjah Mada \\ ${ }^{2}$ Program Diploma IV Teknologi Jaringan, Sekolah Vokasi, Universitas Gadjah Mada \\ ${ }^{2}$ hnisnianto@gmail.com
}

\begin{abstract}
Abstrak
Sungai merupakan salah satu kebutuhan hidup bagi sebagian masyarakat yang hidup di daerah bantaran sungai, tetapi ketika musim penghujan air sungai dapat meluap dan berpotensi banjir di beberapa kawasan sehingga dapat menyebabkan kerugian harta benda dan bahkan korban jiwa dikarenakan terlambatnya informasi air sungai yang meluap. Twitter merupakan jejaring sosial yang memungkinkan penggunanya untuk mengirim dan membaca pesan berbasis teks secara cepat update dan realtime hingga 140 karakter. Prototipe sistem terdiri dari sensor ultrasonik HC-SR04 untuk membaca ketinggian air, Arduino Uno R3, dan Ethernet Shield compatible Arduino untuk menghubungkan ke jaringan komputer agar dapat di posting langsung ke twitter secara otomatis. Hasil pengujian menunjukkan bahwa sistem ini mampu memberikan informasi ketinggian air yang dikatagorikan kondisi aman, waspada, siaga, dan bahaya secara realtime dan broadcast melalui media sosial Twitter secara berkala.
\end{abstract}

Kata kunci: Banjir, Informasi, Mikrokontroler Arduino, Twitter, Ultrasonik

\begin{abstract}
The river is one of the necessities of life for some people who live in the area along the river, but when the rainy season the river water may overflow and potentially flooding in some areas that can cause loss of property and even loss of life due to late information overflow of river water. Twitter is a social network that allows users to send and read text-based messages quickly and realtime updates up to 140 characters. The prototype system consists of HC-SR04 ultrasonic sensor to read the water level, Arduino Uno R3 and Arduino Ethernet Shield compatible to connect to a computer network in order to be able to post directly to Twitter automatically. The results show that the system is able to provide information about water levels were categorized safe condition, alert, alert, and danger in realtime and broadcast through social media Twitter regularly.
\end{abstract}

Keywords: Flood, Information, Microcontroller Arduino, Twitter, Ultrasonic 


\section{PENDAHULUAN}

Banjir merupakan fenomena alam yang seringkali menjadi ancaman nyata terutama saat musim penghujan tiba karena beberapa daerah di Indonesia banyak aliran sungai. Banjir adalah naiknya air sungai kemudian meluap di suatu kawasan hingga menutupi permukaan daratan di kawasan tersebut [1].

Curah hujan yang terus menerus menyebabkan naiknya air sungai di sekitar pemukiman warga sehingga dapat berpotensi banjir. Luapan air sungai sering datang tanpa diduga karena minimnya peringatan dini terhadap bahaya banjir sehingga menimbulkan banyak kerugian bagi masyarakat baik itu materi maupun ancaman kesehatan [2].

Selama ini pemantauan ketinggian air sungai dilakukan secara manual dengan cara datang langsung ke sungai sehingga kurang efisien. Otomatisasi menjadi pilihan yang tepat dan menguntungkan didukung oleh penyebaran informasi semakin mudah dilakukan diantaranya melalui telepon seluler, internet, dan media sosial. Akses internet saat ini semakin mudah, sehingga media sosial seperti Facebook, Twitter, Pinterest, Instagram, dan Tumbrl semakin banyak digunakan. Hasil penelitian menunjukkan bahwa 67\% pengguna internet menggunakan media sosial. Indonesia berada pada urutan ke lima, dan Jakarta merupakan pengguna terbanyak. [3] [4] Pengguna twitter di Indonesia jumlahnya mencapai 50 juta dan di prediksi akan terus bertambah di masa depan karena dapat menghubungkan banyak orang dan menjadi wadah untuk membicarakan berbagi hal yang sedang terjadi, mulai informasi banjir, macet, termasuk Wapres untuk berhubungan dengan masyarakatnya [5,6].

Penelitian ini mengembangkan prototipe sistem informasi ketinggian air sungai secara otomatis dan realtime menggunakan media sosial twitter, sehingga diharapkan dapat membantu memberikan peringatan apabila terjadi kenaikan air, serta dapat dilakukannya pencegahan dini terhadap bahaya banjir.

\section{DASAR TEORI DAN METODOLOGI}

\subsection{Perancangan Sistem}

Sistem yang dibuat seperti pada Gambar 1.

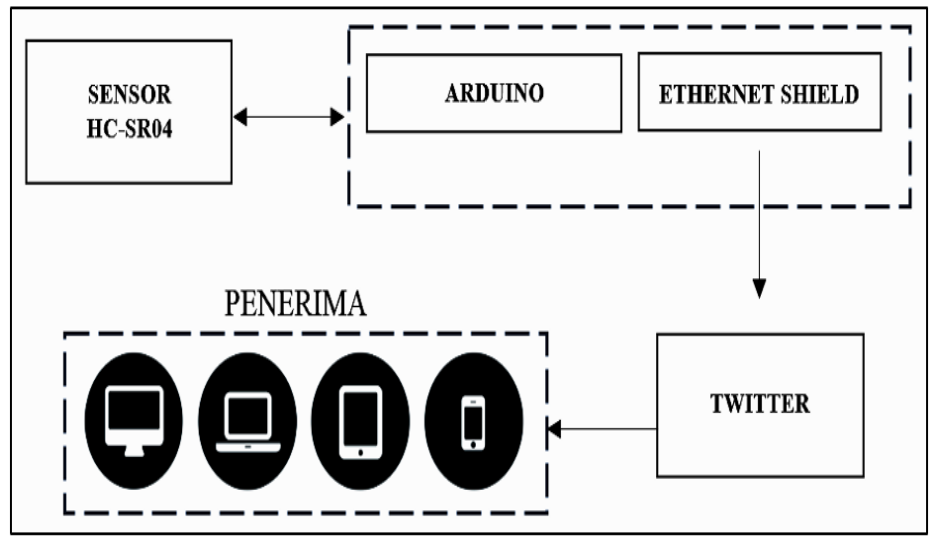

Gambar 1. Blok Diagram Sistem yang direncanakan

Data ketinggian air di ukur dengan menggunakan sensor ultrasonic HC-SR04 kemudian diolah oleh Arduino. Ethernet Shield berfungsi untuk mengirimkan hasil pembacaan ketinggian permukaan air ke server twitter melalui jaringan internet. 


\subsection{Sensor HC-SR04}

Sensor HC-SR04 berfungsi sebagai pengukur ketinggian permukaan air yang terhubung dengan Arduino pada pin VCC, GND, pin 6 ke Trigger, dan pin 5 ke Echo seperti pada Gambar 2(a) dan 2(b) [7].

\subsection{Arduino dan Ethernet Shield}

Arduino berfungsi sebagai pengendali utama dan memproses perintah untuk dikirim ke server twitter. Fungsi Ethernet Shield untuk menghubungkan Arduino ke jaringan komputer. Penggunaan Ethernet Shield pada Arduino seperti pada Gambar 2(a).[8] [9] [10]

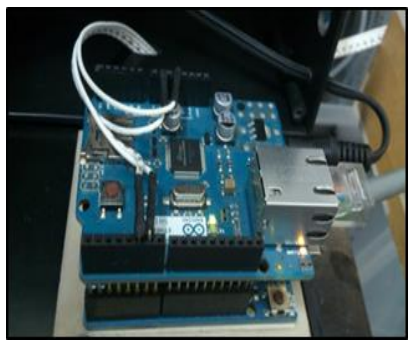

(a)

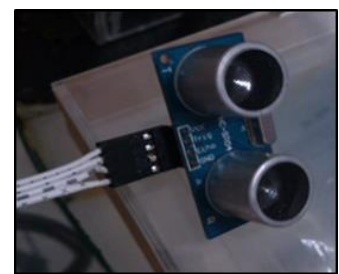

(b)

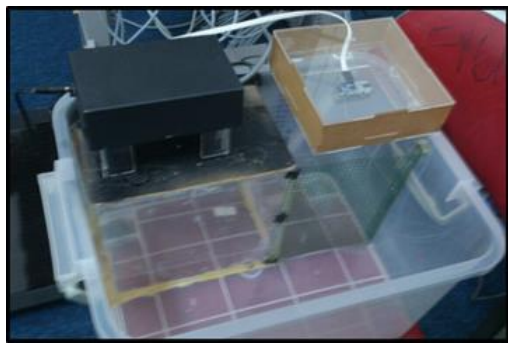

(c)

Gambar 2.(a) Arduino dengan Ethernet Shield terpasang, (b). Sensor ketinggian dengan HC-SR04, (c).Prototipe Ketinggian Air

\subsection{Twitter Tokens}

Token diperlukan untuk mengirim pesan dengan Open Authentification (OAuth) yang berfungsi untuk mendapatkan akses ke penyedia layanan tanpa harus meminta credential. Token diperoleh dengan mengakses https://arduino-tweet.appspot.com/oauth/twitter/login seperti pada Gambar 3.a..[11][12[13]

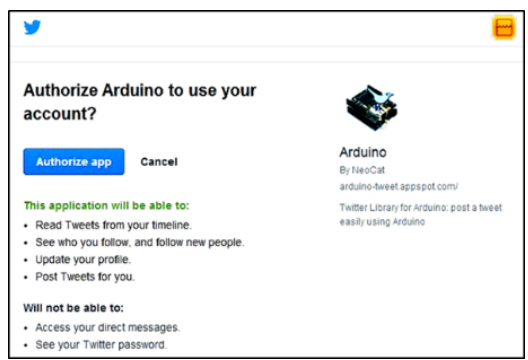

(a)

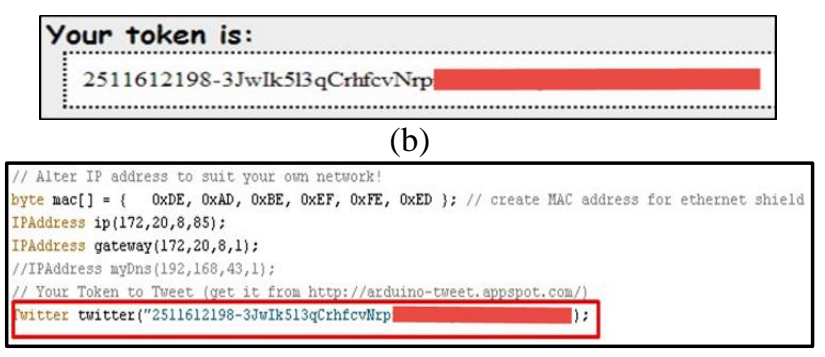

(c)

Gambar 3.(a) Halaman Open Authentification (OAuth), (b). Request Token, (c). Token Twitter pada program

Authorize app digunakan untuk request token pada server Twitter supaya langsung merespon dan memberikan akses token dari akun. Token yang didapat dari hasil request seperti pada Gambar 3.b. Token tersebut yang selanjutnya dimasukan kedalam program seperti Gambar 3.c [10].

Penerima merupakan device yang dapat digunakan oleh masyarakat untuk mengakses media Twitter. Dari akun penerima yang sudah mem-follow akun Twitter, sistem akan muncul postingan berupa informasi dari ketinggian air seperti pada Gambar 4. 


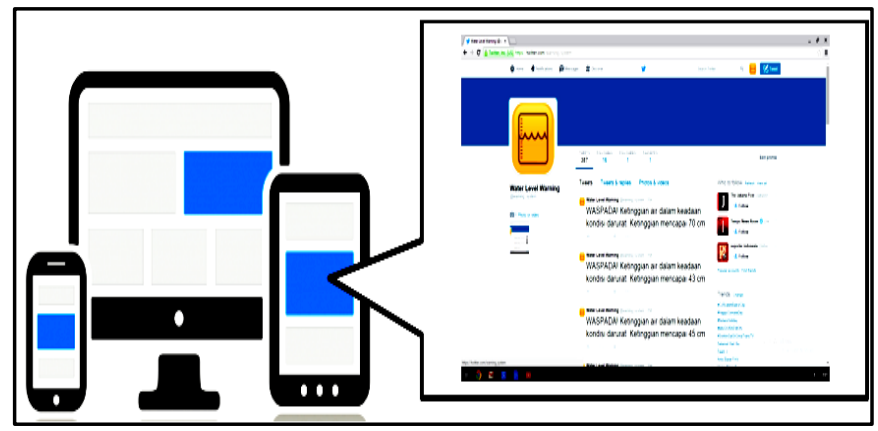

Gambar 4. Informasi pada device penerima

\subsection{Diagram Alir (Flow Chart)}

Gambar 5 adalah diagram alir dari sistem.

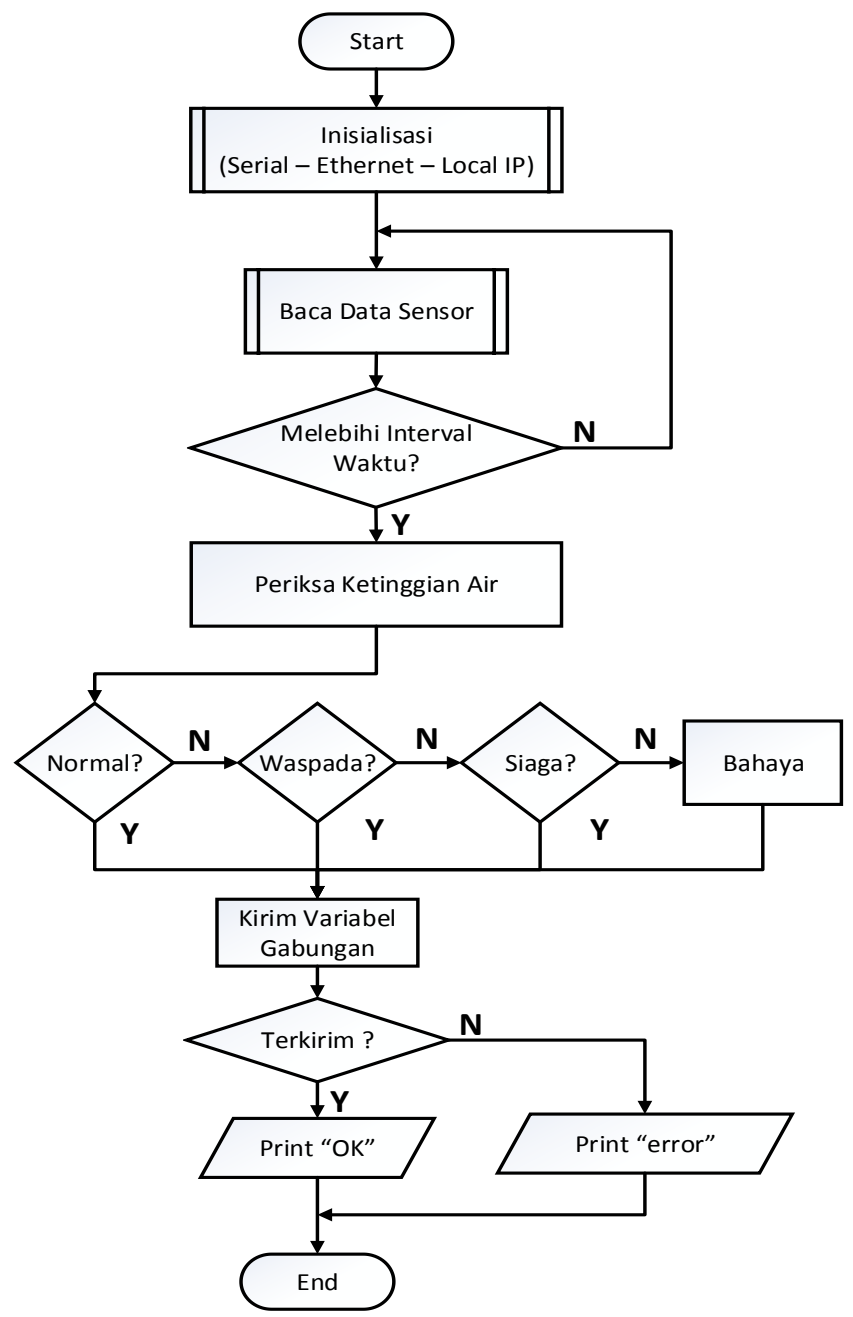

Gambar 5. Flowchart sistem yang diusulkan

\section{ANALISIS DAN PEMBAHASAN}

\subsection{Serial Monitor}

Koneksi Arduino dengan serial port komputer serta-Ethernet Shield yang terhubung ke jaringan komputer menggunakan kabel UTP dengan konektor RJ-45 yang di cramping crossover, jika berhasil muncul status "Connected to IP address: 172.20.8.85" dan pembacaan sensor dimulai. Hasilnya ditampilkan pada serial monitor seperti yang terlihat pada Gambar 6. 


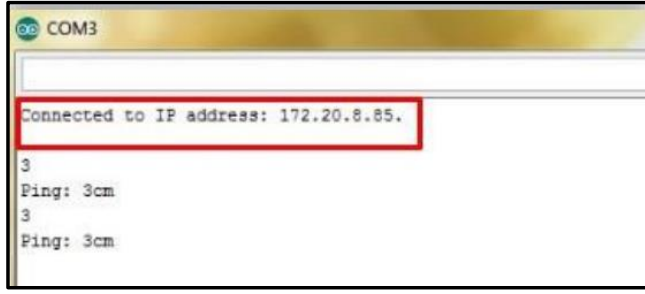

Gambar 6. Serial Monitor Arduino

\subsection{Kondisi Normal}

Kondisi normal ketinggian $1-8 \mathrm{~cm}$. Ketika ketinggian air $6 \mathrm{~cm}$ seperti pada Gambar 7.a, maka termasuk dalam kategori normal. Sensor akan melakukan ping secara berkala dengan waktu interval yang telah ditentukan. Setelah interval 1 menit maka akan terhubung ke twitter dan data hasil pembacaan sensor akan langsung dikirim ke twitter seperti yang terlihat pada tampilan serial monitor pada Gambar 7.b.

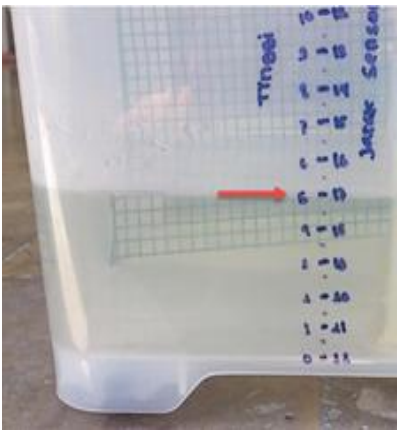

(a)

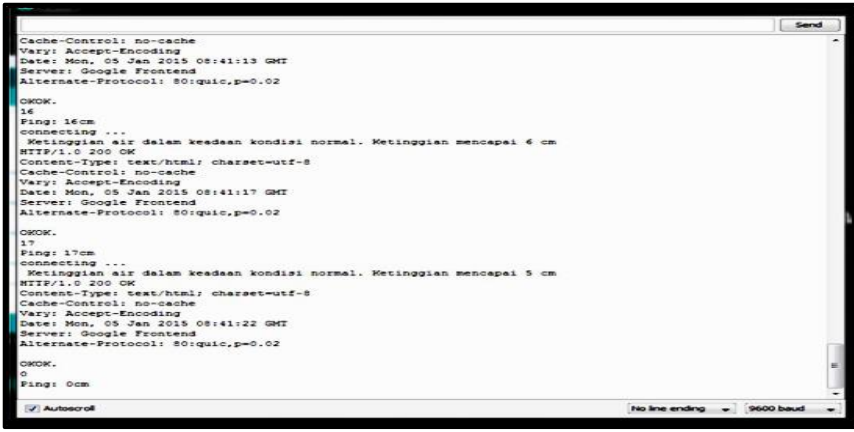

(b)

Gambar 7.(a) Ketinggian air dalam kondisi normal (b) Informasi kondisi normal lewat Serial Monitor

Setelah terhubung ke jaringan, maka informasi akan diposting ke Twitter dan akan diterima dan ditampilkan seperti pada Gambar 8.

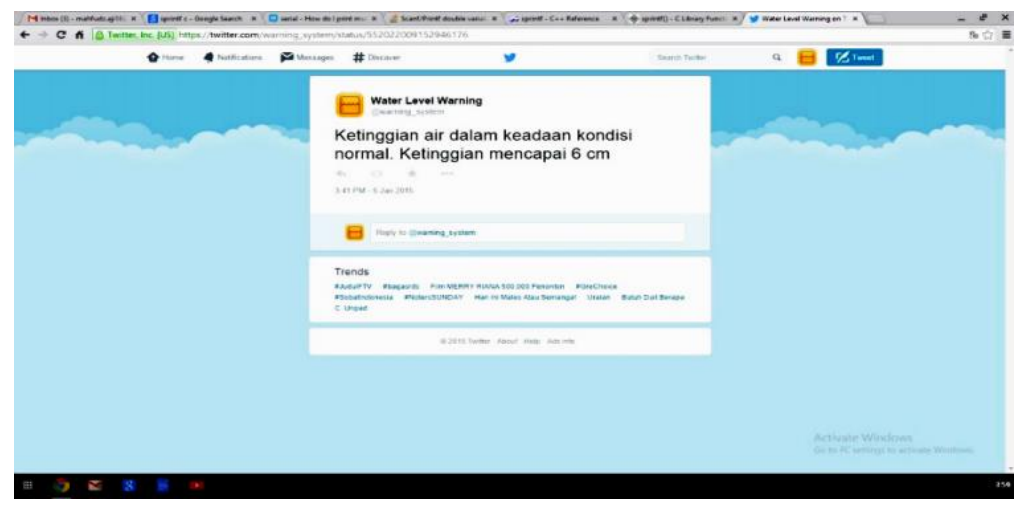

Gambar 8. Informasi kondisi normal pada Twitter

Dari Gambar 8 terlihat bahwa sistem berhasil mengirimkan informasi ketinggian air pada level normal ke jejaring sosial Twitter dan diterima oleh follower mengenai kondisi ketinggian air saat ini.

\subsection{Kondisi Waspada}

Kondisi waspada ketika ketinggian air diatas $8 \mathrm{~cm}$ hingga kurang dari sama dengan $12 \mathrm{~cm}$. Pada percobaan dilakukan penambahan volume air sehingga mencapai ketinggian $9 \mathrm{~cm}$ seperti pada Gambar 9.a. 


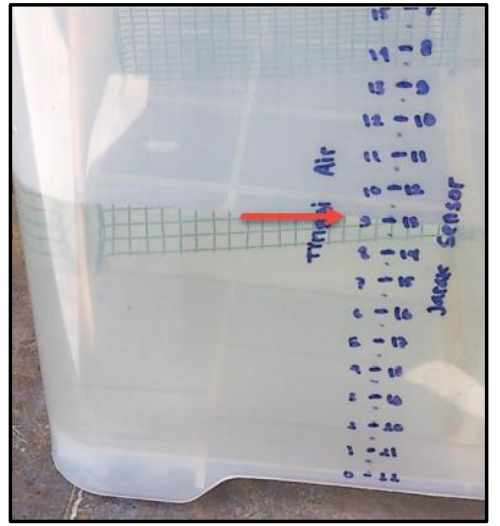

(a)

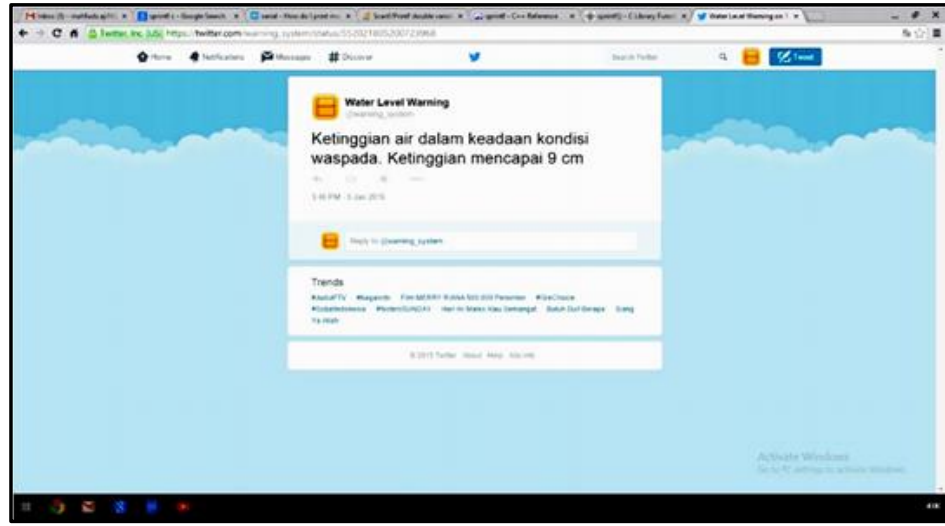

(b)

Gambar 9. (a). Penambahan volume air hingga ketinggian $9 \mathrm{~cm}$ (b). Informasi kondisi waspada pada Twitter

Gambar 9.a ketinggian air yang meningkat menjadi $9 \mathrm{~cm}$ sehingga statusnya menjadi waspada. Setelah interval waktu 1 menit, maka informasi ketinggian air ini langsung dikirim ke Twitter dan diterima pada komputer sebagai follower seperti pada Gambar 9.b.

\subsection{Kondisi Siaga}

Kondisi siaga jika ketinggian air lebih dari $13 \mathrm{~cm}$ sampai kurang dari sama dengan 15 $\mathrm{cm}$. Ketinggian yang terukur adalah $14 \mathrm{~cm}$ seperti pada Gambar 10.a.

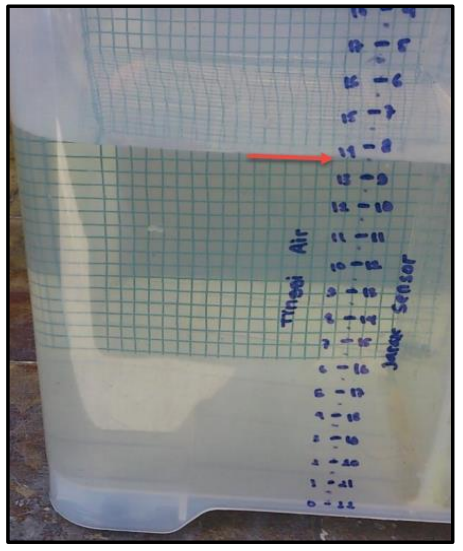

(a)

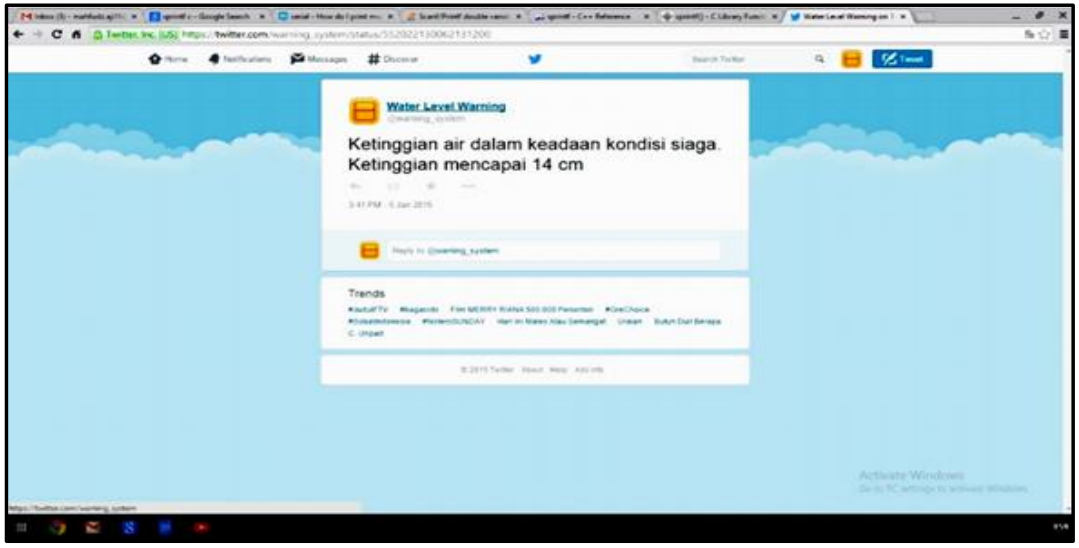

(b)

Gambar 10. (a) Penambahan volume air hingga ketinggian $14 \mathrm{~cm}$ (b).Informasi kondisi siaga pada Twitter

Pada Gambar 10.a ketinggian air yang meningkat menjadi $14 \mathrm{~cm}$, maka statusnya menjadi siaga. Informasi kondisi siaga pada Twitter seperti pada Gambar 10.b. Apabila sudah muncul status siaga seperti ini diharapkan warga cepat tanggap melakukan antisipasi karena tidak menutup kemungkinan statusnya akan naik menjadi bahaya.

\subsection{Kondisi Bahaya}

Kondisi bahaya jika ketinggian air diatas $15 \mathrm{~cm}$. Status bahaya dapat berpotensi terjadinya banjir. Pada percobaan dilakukan penambahan volume air hingga $16 \mathrm{~cm}$ seperti pada Gambar 11.a. 


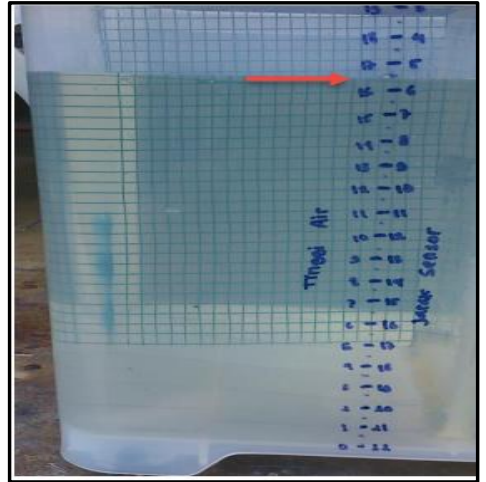

(a)

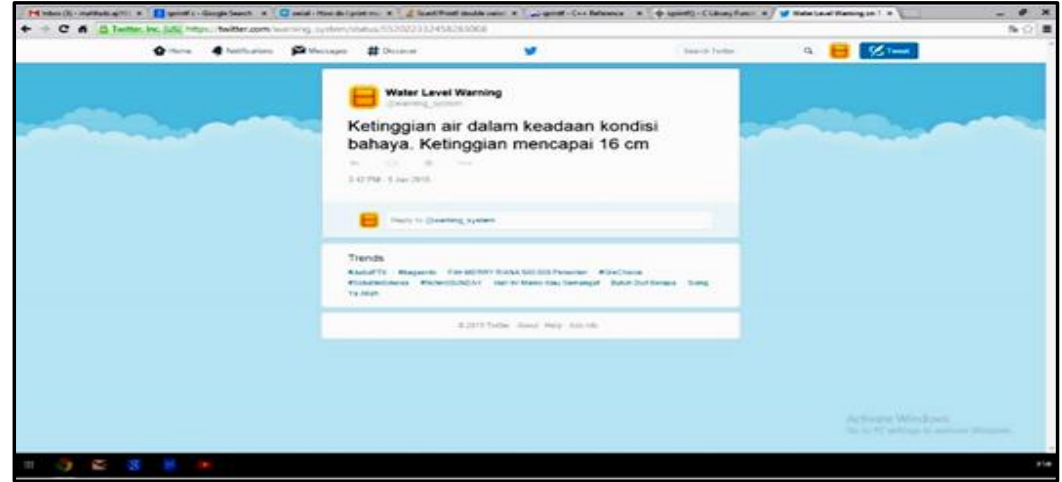

(b)

Gambar 11. (a)Penambahan volume air hingga ketinggian $16 \mathrm{~cm}$ (b).Informasi kondisi bahaya pada Twitter

Pada Gambar 11.a ketinggian air mencapai $16 \mathrm{~cm}$ dan masuk kondisi bahaya. Ketinggiannya akan langsung terbaca dan ke Twitter seperti pada Gambar 411.b. Perubahan ketinggian air akan terus menerus dibaca oleh sensor dan akan di posting ke server Twitter dan dapat diterima oleh semua follower.

Sewaktu-waktu dapat terjadi error (returns error 403) dikarenakan twitter akan menolak pengulangan konten pesan yang sama. Jika data yang terukur memiliki nilai yang sama, maka yang terposting di Twitter hanya satu data saja. Apabila data yang terukur berubah-ubah secara berkala maka data akan di posting semua ke Twitter.

\subsection{Tampilan hasil pembacaan pada Twitter}

Setelah terhubung ke twitter, secara otomatis beberapa kondisi diatas akan langsung di posting di akun Twitter seperti yang terlihat pada Gambar 12.

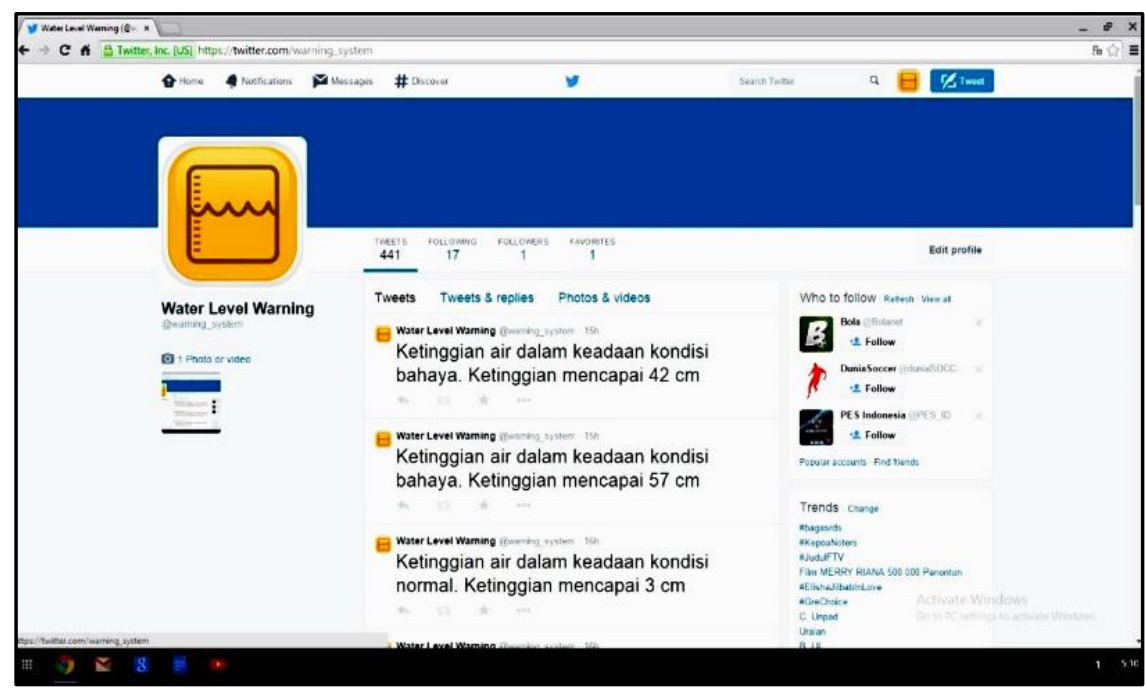

Gambar 12. Tampilan posting pada Twitter lewat Desktop 


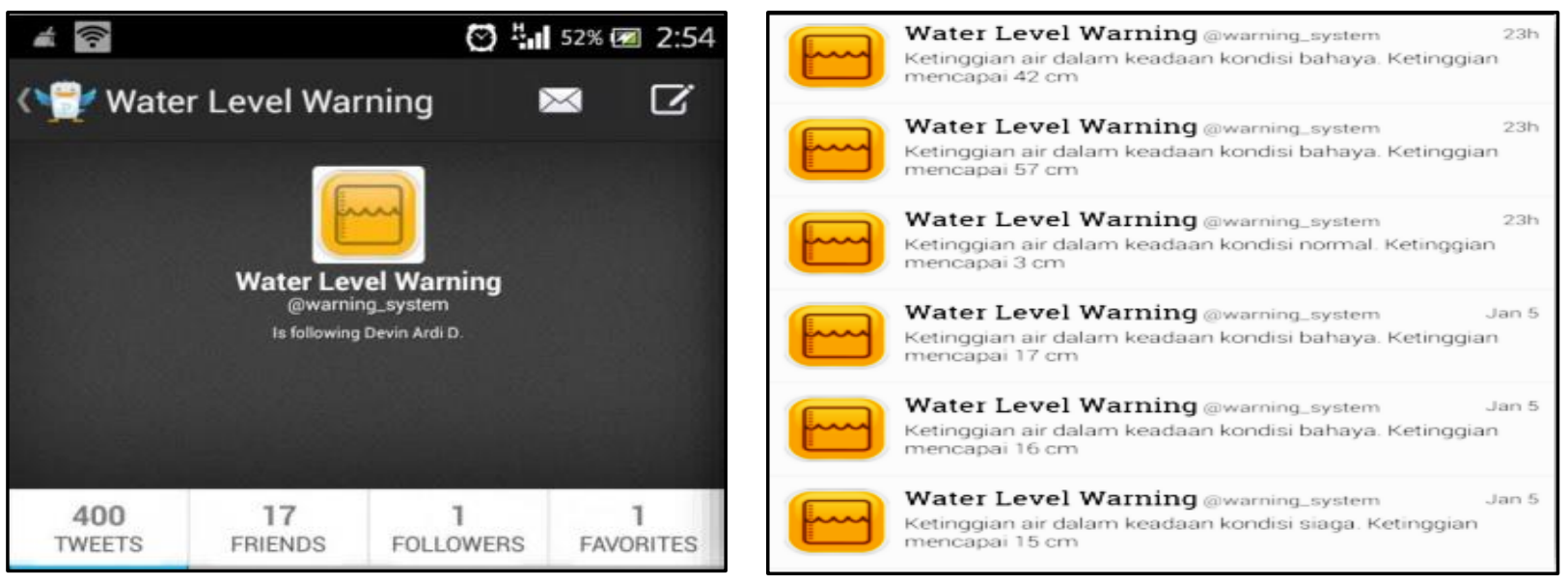

Gambar 13. Tampilan posting pada Twitter lewat mobile

Dari tampilan twitter pada Gambar 12 dapat dilihat hasil pembacaan sensor ketinggian berdasarkan beberapa kondisi pada program berhasil dikirimkan ke Twitter. Dengan begitu informasi dapat langsung diterima oleh followers karena tweet langsung muncul pada timeline Twitter. Pastikan untuk follow akun agar dapat mengetahui informasi secara langsung, sehingga dapat melakukan penanggulangan akan bahaya banjir yang bisa saja terjadi akibat naiknya ketinggian air sungai. Tampilan posting pada Twitter dapat juga diakses melalui mobile seperti pada Gambar 13.

\section{KESIMPULAN}

Kesimpulan yang diperoleh dari penelitian ini adalah sebagai berikut :

1. Sistem informasi ini bekerja dengan baik dan dapat memberikan penyebaran informasi secara realtime dan broadcast melalui media sosial Twitter.

2. Dengan interval waktu yang dapat ditentukan, sistem akan mengirimkan Tweet secara berkala sesuai kondisi ketinggian air yang terbaca oleh sensor.

3. Kualitas jaringan internet berpengaruh pada jeda waktu (delay) dari pembacaan sensor dengan Tweet.

4. Jejaring sosial Twitter sebagai media informasi ketinggian air mempermudah untuk mengetahui perubahan ketinggian air sungai tanpa harus memeriksa secara langsung, sehingga penanggulangan dini terhadap terjadinya banjir dapat dilakukan secara cepat tanggap.

\section{DAFTAR PUSTAKA}

[1] Yuniretnan, 2010, Pengertian Banjir, http://elib.unikom.ac.id/files/disk1/660/jbptunikomppgdl-yuniretnan-32988-10-unikom_y-i.pdf

[2] Somantri, Lili,. 2008. Pemanfaatan Teknik Pengindraan Jarak Jauh Untuk Mengidentifikasi Kerentanan dan Resiko Banjir. Jurnal Geografi/ GEA.

[3] Prihadi, Susetyo, Dwi., 2015, Berapa Jumlah Pengguna Facebook dan Twitter di Indonesia? Terdapat di http://www.cnnindonesia.com/teknologi/20150327061134-185-42245/berapajumlah-pengguna-facebook-dan-twitter-di-indonesia/ [akses Rabu, 06 Mei 2015]

[4] Heni, 2013, Riset Pengguna Social Media 2013 terdapat di http://artikelinformasi.com/risetpengguna-social-media-2013/ [akses Rabu, 06 Mei 2015] 
[5] Hasibuan, Noor, Aspasia., 2015, Jumlah Pengguna Twitter di Indonesia Akhirnya Terungkap terdapat di http://www.cnnindonesia.com/teknologi/20150326141025-185-42076/jumlahpengguna-twitter-di-indonesia-akhirnya-terungkap/ [akses Rabu, 06 Mei 2015]

[6] Hasibuan, Noor, Aspasia., 2015, CEO Twitter Ungkap Alasan Buka Kantor di Jakarta terdapat di http://www.cnnindonesia.com/teknologi/20150326143748-185-42087/ceotwitter-ungkap-alasan-buka-kantor-di-jakarta/ dikses Rabu, 06 Mei 2015]

[7] HC-SR04 Datasheet [online] http://www.electroschematics.com/8902/hc-sr04-datasheet/ , [akses 10 Desember 2014]

[8] Arduino Team, 2014, Arduino Ethernet Shield, http://arduino.cc/en/Main/ArduinoEthernetShield, [akses 10 Desember 2014]

[9] Blum, Jeremy., 2013, Exploring Arduino ${ }^{\circledR}:$ Tools and Techniques for Engineering Wizardry, Indianapolis, USA, John Wiley \& Sons, Inc.

[10] Boxall, John., 2013, Arduino Workshop : A hands - on introduction with 65 projects, San Francisco, USA, No Starch Press, Inc.

[11] Yates, Darren., 2013, How to tweet with your Arduino, http://apcmag.com/how-to-tweetwith-your-arduino.html, [akses 6 Desember 2014]

[12] Anggriawan, E.A., 2104, Tutorial Membuat API Key, Consumer Token, Access Key untuk Twitter OAuth, http://www.ekospinach.co.vu/2014/10/tutorial-membuat-api-key-consumertoken.html , [akses 20 Desember 2014]

[13] __ 2011, Tweet Library for Arduino, Post messages to Twitter (tweet) from Arduino with Ethernet Shield, https://arduino-tweet.appspot.com/, [akses 9 Desember 2014]. 